\title{
Should different gaseous contaminants be treated differently in CFD indoor simulations?
}

\author{
R. N. Zhuang ${ }^{1}, \mathrm{X} \cdot \mathrm{Li}^{1} \& \mathrm{~J} . \mathrm{Tu}^{1,2}$ \\ ${ }^{1}$ School of Aerospace, Mechanical and Manufacturing Engineering, \\ RMIT University, Australia \\ ${ }^{2}$ Department of Building Science, Tsinghua University, China
}

\begin{abstract}
Gaseous contaminants such as volatile organic compounds (VOCs) are the major contaminants in indoor air. As there are hundreds of VOCs existing in the indoor environment simultaneously, many CFD practitioners may wonder: should different VOCs be treated differently in CFD indoor simulations? A key factor in CFD simulation to distinguish different VOCs is the kinetic diffusivity, which is negatively associated with the molar mass of a gaseous contaminant, thus could differ a lot for different VOCs. If there are significant discrepancies in transport behaviours of different VOCs, the reason could be due to large differences in their diffusivities. In order to find out the answer of the question in the title of this paper, this study designed a CFD model in which two imaginary VOCs were emitted from the same location at the same emission rate; the only difference is that the diffusivity of the lighter VOC is eight times as much as the diffusivity of the heavier VOC. Simulation results showed that, in terms of steady state, the distribution patterns of different VOCs were almost the same in a normally ventilated room. Therefore all gaseous contaminants can be treated in the same way by applying a typical diffusivity value $10^{-5} \mathrm{~m}^{2} / \mathrm{s}$ in CFD simulation. Keywords: gaseous contaminant, VOC, diffusivity, CFD, indoor air.
\end{abstract}

\section{Introduction}

Indoor air quality could be affected by a number of pollutants such as secondhand smoke, volatile organic compounds (VOCs), asbestos fibres, biological particles, radon, carbon monoxide, etc. [1], and gaseous contaminants are considered to be a very important category. A few gaseous contaminants 
are inorganic such as carbon monoxide and hydrogen sulphide, while most gaseous contaminants are organic and best known as volatile organic compounds (VOCs). It has been known for a long time that there are at least several hundreds of gaseous contaminants in indoor environment [2]. Researchers used experimental devices such as Gas chromatography-mass spectrometry (GC/MS) to identify VOCs in particular environments [3, 4]. VOCs may have adverse health effects $[5,6]$, therefore are of serious concern in indoor air quality. Experimental methods have been applied to monitor the concentration level of VOCs at some particular locations in the room $[4,7]$.

As a convenient replacement of experimental methods, computational fluid dynamics (CFD) has been increasingly used to simulate the transport of gaseous contaminants [8-12]. The diffusivity of the targeted gaseous contaminant must be known for CFD simulations. Diffusivity (or diffusion coefficient) is a proportional constant between the molar flux due to molecular diffusion and the gradient in the concentration of the species. According to classic theories such as Graham's Law and Chapman-Enskog theory [13], diffusivity is negatively related to the molar mass of gas, and this point has been proved by many experiments. For example, tetracontylamine $(\mathrm{C} 40 \mathrm{H} 83 \mathrm{~N})$ has a molar mass 577 and a predicted diffusivity $0.0244 \mathrm{~cm}^{2} / \mathrm{s}$ while methyl fluoride $(\mathrm{CH} 3 \mathrm{~F})$ has a molar mass 34 and a predicted diffusivity $0.146 \mathrm{~cm}^{2} / \mathrm{s}$, which is six times as much as the diffusivity of tetracontylamine [14]. Therefore a gas with lighter molar mass would be easy to diffuse in the certain environment than a heavier gas. As there are hundreds of different VOCs in indoor environment, a key question thus arises: Is the transport behaviour of a lighter VOC significantly different from that of a heavier VOC due to the large difference in their diffusivities? In terms of CFD practice, should different gaseous contaminants be treated differently in CFD indoor simulations due to their different diffusivities?

There were few articles in literature that discussed behaviours of different VOCs in indoor environment. Farajollahi et al. [15] used experimental approach to investigate diffusivities of five VOCs under different environmental conditions of temperature and humidity; however, the effect of the differences between diffusivities on transport of VOCs had not been investigated and compared. Yang et al. [10] undertook interesting CFD simulation by investigating concentration distributions of four different VOCs in a small test chamber. The time-dependant concentration graphs of four different VOCs showed very similar curves. However, such similarity had not been highlighted and discussed in their conclusion part. In summary, the question that this study is concerned has not been directly addressed or answered in literature.

Also in literature, the value of the diffusivity of a particular gas varies due to different theoretical prediction models or different experimental methods [16, 17]. CFD practitioners sometimes have to arbitrarily select one value among many choices. Therefore, another question arises: Is the accuracy of diffusivity important in CFD simulation about transport of gaseous contaminant in indoor environment? In other words, are the CFD simulation results sensitive to the value of diffusivity? 
The aim of this study is to try to find out the role of diffusivity in the distribution process of gaseous contaminants in indoor environment. In order to achieve this aim, this study designed a CFD model for a test chamber, in which two imaginary VOCs (called VOC1 and VOC2 respectively hereinafter) were emitted from the same location at the same emission rate. The only difference is that: the diffusivity of VOC1 is 8 times as much as the diffusivity of VOC2. CFD simulations were run under transient as well as steady state scenarios, and then the concentration profiles of the two VOCs were compared to each other. If there were no significant discrepancy in the distribution patterns of these two VOCs, it would be sufficient to say that diffusivity is not important in the transport process of gaseous contaminant in indoor environment.

\section{Methodology}

The geometry of the CFD model in this study is shown in Figure 1.

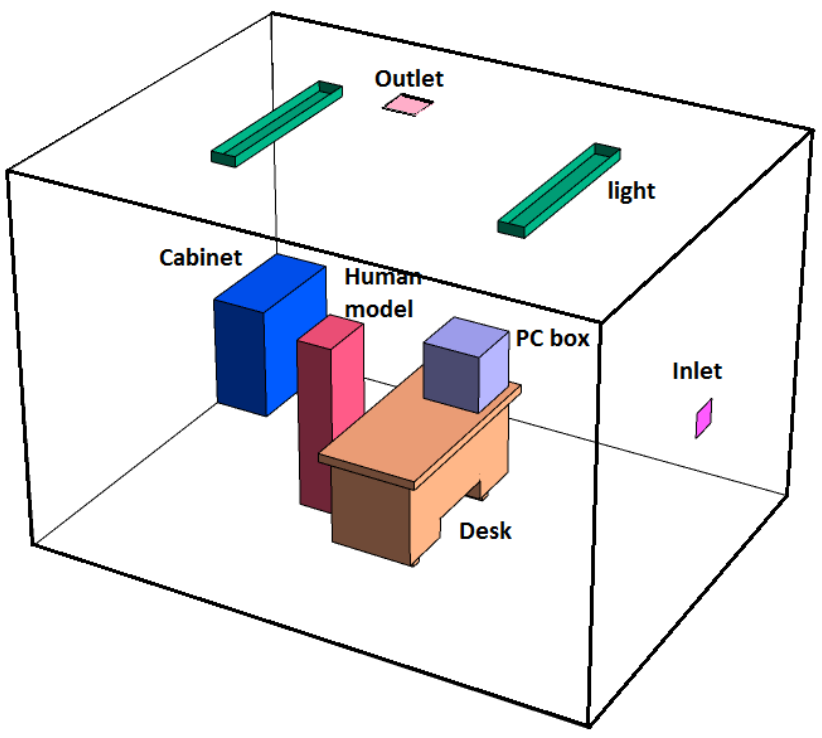

Figure 1: Test chamber in the CFD model of this study.

The room is $3.90 \mathrm{~m}(\mathrm{~L}) \times 2.90 \mathrm{~m}(\mathrm{~W}) \times 2.60 \mathrm{~m}(\mathrm{H})$ with two lights on the ceiling; a cabinet, which is emitting VOC1 and VOC2 simultaneously at the same emission rate $10^{-9} \mathrm{~kg} /\left(\mathrm{m}^{2} \mathrm{~s}\right)$, is standing in the corner with sizes of $0.80 \mathrm{~m}$ $(\mathrm{L}) \times 0.40 \mathrm{~m}(\mathrm{~W}) \times 0.80 \mathrm{~m}(\mathrm{H})$. A human model $(0.4 \mathrm{~m} \times 0.25 \mathrm{~m} \times 1.2 \mathrm{~m})$ and a desk $(1.30 \mathrm{~m} \times 0.68 \times 0.70 \mathrm{~m})$ are in the middle of the room. A box $(0.40 \mathrm{~m} \times 0.40$ $\times 0.40 \mathrm{~m})$ on the desk represents a computer. Air of $25^{\circ} \mathrm{C}$ is blown into the room from the inlet $(0.21 \mathrm{~m} \times 0.17 \mathrm{~m})$, which is located in the middle of the front wall, while the outlet $(0.24 \mathrm{~m} \times 0.24 \mathrm{~m})$ is located on the ceiling beside one light. Tian et al. [12] had used a very similar model to do both experiment and CFD 
simulation, and their CFD results were in acceptable agreement with their experimental data.

The human model, the computer box and two lights are heat sources in the CFD model. Heat loads are summarised in Table 1.

Table 1: Heat loads.

\begin{tabular}{lc}
\hline Heat source & Heat load (W) \\
\hline Human & 70 \\
Computer & 130 \\
Lights & $40 \times 2$ \\
\hline
\end{tabular}

The commercial program CFX in ANSYS 13.0 has been chosen to run CFD simulations for both transient and steady states under three different ventilation conditions (i.e. six cases in Table 2). For transient simulations, the initial velocities of all points in the room were set to be $0 \mathrm{~m} / \mathrm{s}$, thus it is assumed that there is no airflow in the room at start.

Table 2: $\quad$ Six cases of CFD simulation.

\begin{tabular}{|c|c|c|}
\hline & Transient & Steady state \\
\hline $0.3 \mathrm{~m} / \mathrm{s}$ inlet wind speed $(v)$, or & Case 1 & Case 2 \\
$140 \%$ air change per hour $(\mathrm{ACH})$ & & \\
\hline$v=1.2 \mathrm{~m} / \mathrm{s}$, or $\mathrm{ACH}=550 \%$ & Case 3 & Case 4 \\
\hline $\mathrm{v}=2.2 \mathrm{~m}$, or $\mathrm{ACH}=1000 \%$ & Case 5 & Case 6 \\
\hline
\end{tabular}

ANSYS CFX 13.0 has incorporated many thermal dynamics equations and models, some of which need to be selected in CFX-Pre according to conditions and requirements of this particular study. Due to very low concentration of gaseous contaminant in indoor environment, the transport of gaseous contaminant is assumed to be controlled by the airflow thus the existence of gaseous contaminants in the air has no effect on the airflow field. Both VOC1 and VOC2 are modelled by additional variables in CFX-Pre and transport equation for additional variable has been chosen, which has a form of

$$
\frac{\partial(\rho \phi)}{\partial t}+\nabla \cdot(\rho \boldsymbol{U} \phi)=\nabla \cdot\left(\rho D_{\phi} \nabla \phi\right)+S_{\phi}
$$


where $\rho$ is the mixture density in mass per unit volume, which approximately equals to the air density due to the very low contaminant concentration. $\Phi$ is the gaseous contaminant quantity per unit volume while $\phi=\Phi / \rho$ is the gaseous contaminant mass concentration. $S_{\phi}$ is the volumetric source term of the gaseous contaminant, and $D_{\Phi}$ is the kinematic diffusivity of the gaseous contaminant through the air. In this study, the kinematic diffusivity is the main subject, and its value for VOC1 and VOC2 are $1.9 \times 10^{-5} \mathrm{~m}^{2} / \mathrm{s}$ and $2.4 \times 10^{-6} \mathrm{~m}^{2} / \mathrm{s}$ respectively. $D_{\Phi}$ of VOC1 is about eight times as much as $D_{\Phi}$ of VOC2.

Unstructured mesh was adopted in this study. Inflation layers (prisms) were generated around heat sources, while tetrahedrons filled out the room space. The total numbers of mesh elements were about $700 \mathrm{~K}$ for six cases in Table 2 . Mesh independence has been checked and confirmed.

The Re-Normalisation Group (RNG) k- $\varepsilon$ model was regarded as the most accurate model for indoor airflow computation amongst eight different turbulence models investigated by Chen [18]. Therefore this study had selected $\mathrm{RNG} \mathrm{k}-\varepsilon$ model as turbulence model for all cases.

As all boundary conditions for VOC1 and VOC2 were the same except their diffusivities, any significant difference in PD 3-D map could be attributed to the difference between their diffusivities.

\section{Results and findings}

\subsection{Time-dependent contour maps of PD values on sample plan $(\mathrm{z}=0.70 \mathrm{~m})$}

CFD simulations for each case in Table 2 would be able to obtain 3-D concentration profiles for both $\mathrm{VOC} 1$ and $\mathrm{VOC} 2$. The numerical results of VOC1 would be compared to the numerical results of VOC2 by the following index called percentage deviation (PD):

$$
P D=\frac{\left|C_{v o c 1}-C_{v o c 2}\right|}{C_{v o c 2}} \times 100 \%
$$

where $\mathrm{C}_{\mathrm{voc} 1}$ and $\mathrm{C}_{\mathrm{voc} 2}$ are concentration at any particular point in the test room. This study adopted "double 5\%" as a criterion for significant difference in PD: if $\mathrm{PD}$ was greater than $5 \%$ in $5 \%$ of the room space, then the difference in concentrations of VOC 1 and VOC2 would be considered as significant.

A horizontal plan $(\mathrm{z}=0.70 \mathrm{~m})$ was selected as sample plan for presenting contour map of PD values because this plan cut all items in the room, particularly the cabinet that was emitting VOC1 and VOC2 simultaneously at the same rate.

Contour maps in Figure 2 shows results of PD values when air change per hour $(\mathrm{ACH})$ was $140 \%$. It is found that, when $\mathrm{t}=1 \mathrm{~min}$, significant difference (i.e. $\mathrm{PD}>5 \%$ ) in concentrations of two VOCs occurred in more than $50 \%$ of the sample plan area. However, the outstanding area (i.e. area where $\mathrm{PD}>5 \%$ ) was reduced to about $30 \%$ after 5 minutes, and further reduced to less $5 \%$ after 10 minutes. At steady state, no outstanding area was noticeable in the contour map. 

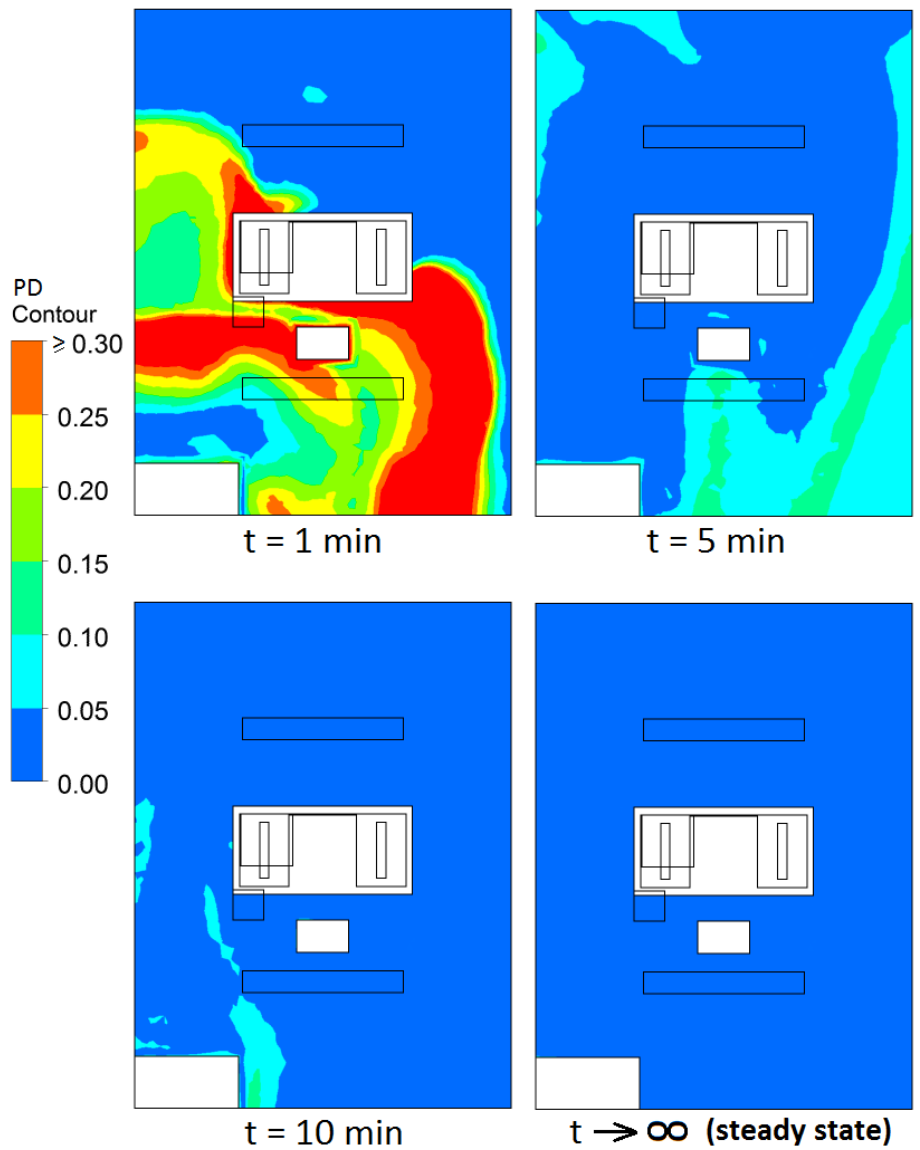

Figure 2: Percentage deviation (PD) contour of two VOCs when $\mathrm{ACH}=140 \%$.

For reference, Figure 3 provides the concentration contours of VOC1 and VOC2 at steady state when $\mathrm{ACH}=140 \%$. It is found that these two contour maps are perfectly identical; this proves that even the eight times difference in their diffusivities of two VOCs makes no recognisable difference on their concentration distributions at steady state.

This study had also run simulations under higher ventilation situations. Figure 4 shows PD values when air change per hour (ACH) was $550 \%$. It is found that, when $\mathrm{t}=1 \mathrm{~min}$, significant difference (i.e. $\mathrm{PD}>5 \%$ ) in concentrations of two VOCs occurred in less than $20 \%$ of the sample plan area. However, the outstanding area (i.e. area where $\mathrm{PD}>5 \%$ ) was reduced to less than $1 \%$ after 2 minutes. At steady state, no outstanding area was noticeable in the contour map. 


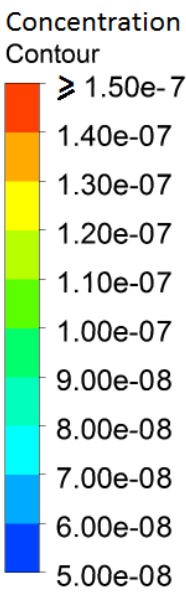

$\left[\mathrm{kg} \mathrm{m}^{\wedge}-3\right]$

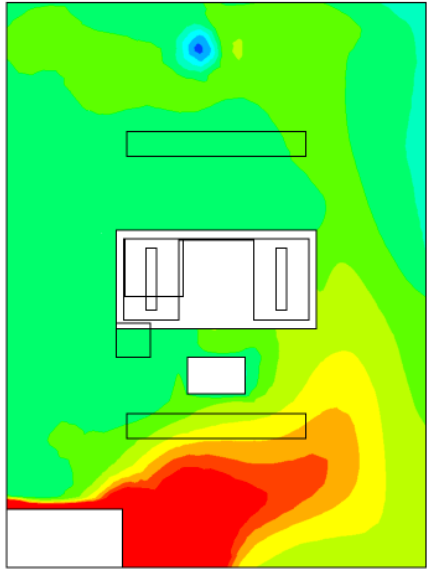

VOC 1 (steady state)

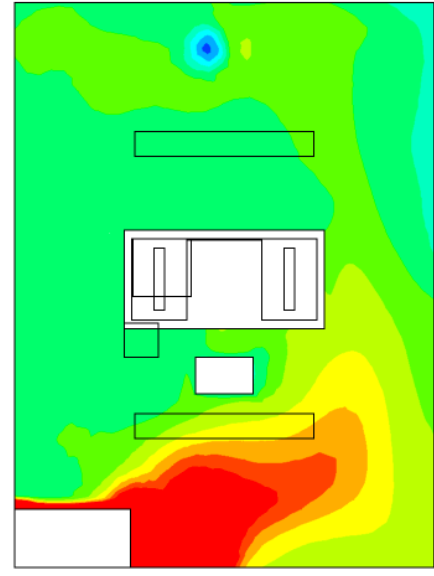

VOC 2 (steady state)

Figure 3: Concentration of VOC1 and VOC2 at steady state when $\mathrm{ACH}=140 \%$.
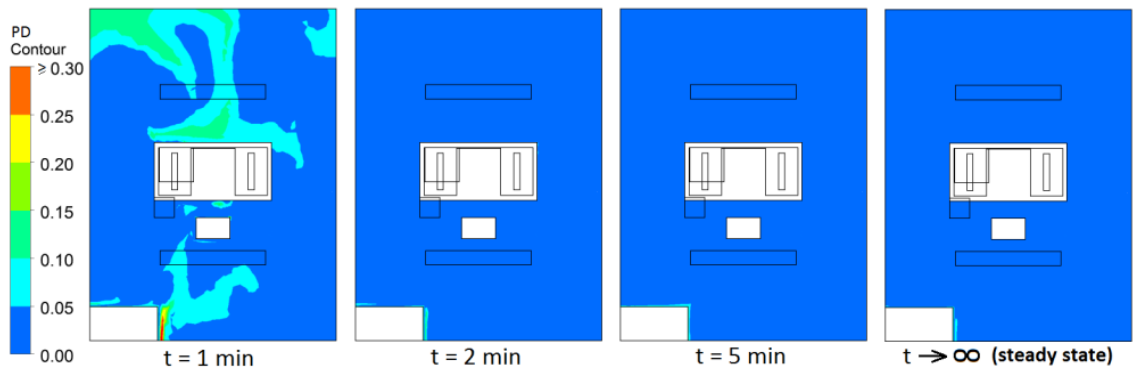

Figure 4: Percentage deviation (PD) contour of two VOCs when $\mathrm{ACH}=550 \%$.

When ventilation rate of the room further increased to $\mathrm{ACH}=1000 \%$, Figure 5 shows that it took less than one minute to make an outstanding area unnoticeable.

The word "unnoticeable" does not mean that the outstanding area is $0 \%$ on the sample plan. When the area very close to the cabinet (i.e. the source of VOC1 and VOC2) was zoomed in, the outstanding area could be identified. Actually, the outstanding area would never disappear even at steady state $(\mathrm{t} \rightarrow \infty)$, but it is too small and too close to cabinet thus hard to be seen.

By reviewing Figures 2, 3, 4 and 5, it can be found that (1) the concentration distributions of VOC1 and VOC2 would eventually reach the same pattern in regardless of the huge difference in their diffusivities; and (2) the larger the air change per hour $(\mathrm{ACH})$ is, the faster the outstanding PD area would shrink. 

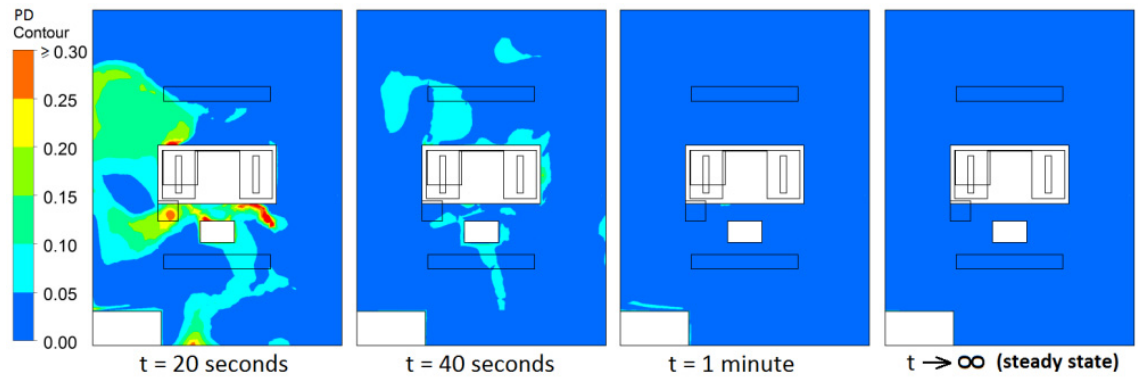

Figure 5: Percentage deviation (PD) contour of two VOCs when $\mathrm{ACH}=1000 \%$.

\subsection{Time-dependent average PD values for the whole room}

Those contour maps in the above Section 3.1 are all on a sample plan $(\mathrm{z}=0.7 \mathrm{~m})$. However, ANSYS CFX 13.0 is able to calculate the average PD values for all mesh elements of the whole room, and the results were summarized in Table 3.

Table 3: Average PD values of the whole room.

\begin{tabular}{|c|c|c|c|c|c|}
\hline & $1 \mathrm{~min}$ & $3 \mathrm{~min}$ & $5 \mathrm{~min}$ & $10 \mathrm{~min}$ & $\mathrm{t} \rightarrow \infty$ \\
\hline $\mathrm{ACH}=1.4$ & $14.80 \%$ & $5.93 \%$ & $3.99 \%$ & $2.36 \%$ & $\rightarrow 0$ \\
\hline $\mathrm{ACH}=5.5$ & $9.13 \%$ & $1.10 \%$ & $0.88 \%$ & $0.42 \%$ & $\rightarrow 0$ \\
\hline $\mathrm{ACH}=10.0$ & $2.34 \%$ & $0.60 \%$ & $0.46 \%$ & $0.24 \%$ & $\rightarrow 0$ \\
\hline
\end{tabular}

The data in Table 3 shows that the larger the ventilation rate is, the faster the average PD value of the room would approach zero. This point is consistent with the results of PD contour analysis in Section 3.1. From the theoretical point of view, a larger ventilation rate means a larger contribution of convection to the transport of gaseous contaminant and a relatively smaller contribution of diffusion process, thus less importance of the diffusivity.

\section{Conclusion}

Three ventilation rates (i.e. $\mathrm{ACH}=140 \%, 550 \%$ and $1000 \%$ ) in this study are all common ventilation rates in real situations such as office rooms, factory plants, school rooms, hospital wards, etc. Conclusions of this study are pertaining to situations in normally ventilated rooms.

Based on the CFD results and findings, Questions that were raised in Introduction part can be collectively answered:

(1) For the transport of gaseous contaminant in a normally ventilated room, if steady state is concerned, the effect of diffusivity is negligible for the whole room except in very small area very close to the contaminant 
source. Even a very large difference in their diffusivities of two gases would not matter because their distributions would approach the same 3-D pattern in the end. In CFD practices, the accuracy of the value of diffusivity is not important. All gaseous contaminants can be treated in the same way by assigning a typical value (e.g. $10^{-5} \mathrm{~m}^{2} / \mathrm{s}$ ) for their diffusivities without affecting the accuracy of the final CFD results of their concentration distributions in steady state.

(2) Even when the time series of concentration distribution in transient simulation is concerned, the effect of diffusivity would soon (i.e. in a few minutes) be overwhelmed by the convection process; all gaseous contaminants can still be treated with the same typical value (e.g. $10^{-5}$ $\mathrm{m}^{2} / \mathrm{s}$ ) for their diffusivities in CFD practices without remarkable error.

\section{Further discussion}

If the ventilation rate is far below normal level (e.g. $\mathrm{ACH}<30 \%$ ), the first conclusion in the above will still hold because it only focuses on steady state; however, the second conclusion might open for debate. The CFD results for $\mathrm{ACH}=140 \%$ in Section 3 showed that it took about 10 minutes for the outstanding area (i.e. area where $\mathrm{PD}>5 \%$ ) to shrink to less than $5 \%$ of the sample plan. Also according Table 3, it would take about 10 minutes for the average PD level in the whole room to drop to around $2 \%$. It can be imagine that, if the ventilation rate decreased too much, it would take considerably longer time for the concentrations of $\mathrm{VOC} 1$ and $\mathrm{VOC} 2$ to reach approximate balance. In theoretical terms, lower $\mathrm{ACH}$ value means longer time for diffusion to perform before it is overwhelmed by convection. If $\mathrm{ACH}$ is too low, then the difference caused by different diffusivities of different gases might no longer be negligible for a considerable length of time.

\section{References}

[1] Austin, J., Brimblecombe, P. \& Sturges, W., Air Pollution Science for the 21st Century, Elsevier Science Ltd, 2002.

[2] Berglund, B., Berglund, U. \& Lindvall, T., Assessment of discomfort and irritation from the indoor air. Proc. of IAQ-86, Atlanta, GA, American Society of Heating Refrigerating and Air Conditioning Engineers, pp. 138-149, 1986.

[3] Krause, C., Mailahn, W., Nagel, R., Schulz, C., Seifert, B. \& Ullrich, D., Occurrence of volatile organic compounds in the air of 500 homes in the Federal Republic of Germany. Proc. of Indoor Air '87, Institute of Water, Soil and Air Hygiene, 1, pp. 102-106, 1987.

[4] Wallace, L., Pellizzari, E. \& Wendel, C. (1991), Total Volatile Organic Concentrations in 2700 Personal, Indoor; and Outdoor Air Samples collected in the US EPA Team Studies. Indoor Air, 1, pp. 465-477, 1991.

[5] Andersson, K., Bakke, J.V., Bjørseth, O., Bornehag, C.G., Clausen, G., Hongslo, J.K., Kjellman, M., Kjærgaard, S., Levy, F., Mølhave, L., 
Skerfving, S. \& Sundell, J., TVOC and Health in Non-industrial Indoor Environments. Indoor Air, 7, pp. 78-91, 1997.

[6] Mølhave, L., Clausen, G., Berglund, B., De Ceaurriz, J., Kettrup, A., Lindvall, T., Maroni, M., Pickering, A. C., Risse, U., Rothweiler, H., Seifert, B. \& Younes, M. (1997), Total Volatile Organic Compounds (TVOC) in Indoor Air Quality Investigations. Indoor Air, 7, pp. 225-240, 1997.

[7] Brown, S. K., Sim, M. R., Abramson, M. J. \& Gray, C. N., Concentrations of Volatile Organic Compounds in Indoor Air - A Review. Indoor Air, 4, pp. 123-134, 1994.

[8] Haghighat, F., Jiang, Z. \& Zhang, Y., The Impact of Ventilation Rate and Partition Layout on the VOC Emission Rate: Time-Dependent Contaminant Removal. Indoor Air, 4, pp. 276-283, 1994.

[9] Huang, H. \& Haghighat, F., Modelling of volatile organic compounds emission from dry building materials. Building and Environment, 37(12), pp. 1349-1360, 2002.

[10] Yang, X., Chen, Q. \& Zhang, J. S., Impact of Early Stage Incomplete Mixing on Estimating VOC Emissions in Small Test Chambers. Indoor Air, 8, pp. 180-189, 1998.

[11] Lin, Z., Chow, T.T., Fong, K.F., Tsang, C.F. \& Wang, Q., Comparison of performances of displacement and mixing ventilations. Part II: indoor air quality. International Journal of Refrigeration, 28, pp. 288-305, 2005.

[12] Tian, L., Lin, Z. \& Wang, Q.W., Comparison of gaseous contaminant diffusion under stratum ventilation and under displacement ventilation. Building and Environment, 45, 2035-2046, 2010.

[13] Piiper, J. \& Worth, H., Value and limits of Graham's law for prediction of diffusivities of gases in gas mixtures. Respiration Physiology, 41(3), pp. 233-240, 1980.

[14] Mirkhani S.A., Gharagheizi F. \& Sattari M., A QSPR model for prediction of diffusion coefficient of non-electrolyte organic compounds in air at ambient condition. Chemosphere, 86(9), pp. 959-966, 2012.

[15] Farajollahi, Y., Chen, Z. \& Haghighat, F., An Experimental Study for Examining the Effects of Environmental Conditions on Diffusion Coefficient of VOCs in Building Materials. Clean Soil Air Water, 37, pp. 436-443, 2009.

[16] Sattari, M. \& Gharagheizi, F., Prediction of molecular diffusivity of pure components into air: A QSPR approach. Chemosphere, 72(9), pp. 12981302, 2008.

[17] Massman, W.J., A review of the molecular diffusivities of $\mathrm{H}_{2} \mathrm{O}, \mathrm{CO}_{2}, \mathrm{CH}_{4}$, $\mathrm{CO}, \mathrm{O}_{3}, \mathrm{SO}_{2}, \mathrm{NH}_{3}, \mathrm{~N}_{2} \mathrm{O}, \mathrm{NO}$, and $\mathrm{NO}_{2}$ in air, $\mathrm{O}_{2}$ and $\mathrm{N}_{2}$ near STP. Atmospheric Environment, 32(6), pp. 1111-1127, 1998.

[18] Chen Q., Comparison of different $\kappa-\varepsilon$ models for indoor airflow computations. Numerical Heat Transfer, 28, pp. 353-69, 1995. 